\title{
Modelling the kinetics of water loss during potato frying with a compartmental dynamic model
}

\author{
R.M. Costa ${ }^{a}$, F.A.R. Oliveira ${ }^{b, *}$ \\ ${ }^{a}$ Escola Superior de Biotecnologia, Universidade Católica Portuguesa, Rua Dr. António Bernardino de Almeida, 4200 Porto, Portugal \\ ${ }^{\mathrm{b}}$ Instituto Inter-Universitário de Macau, Nape, Lote 18, Rua de Londres, Edf. Tap Ik Plaza P, Macau
}

\begin{abstract}
The complexity of the frying process impairs the development of mechanistic models to describe water losses. Empirical models, though lacking a theoretical basis, may provide a suitable and simpler alternative. In this work it was found that a two parallel compartments model (core and edge compartments), with a time-dependent boundary condition, could be successfully applied for this purpose. The model showed a good fit to the experimental data for a variety of experimental conditions tested: potato geometry and size, temperature, oil type and oil use. The core compartment was found to contain about $63 \%$ of the initial potato water content. The rate constants of two-compartments were very sensitive to slice thickness, whereas temperature affected only the rate constant of the core compartment. No significant effects were detected in terms of oil type or oil use. (C) 1999 Elsevier Science Ltd. All rights reserved.
\end{abstract}

Keywords: Parameter estimation; Potato size; Oil type; Oil use; Temperature

\section{Nomenclature}

$D$

$f(t)$

$k$

$K$

$m$

$t$

$T$

Greek symbols

$\alpha$

$\beta$

$\tau$

Subscripts

$0 \quad$ raw potato

c core compartment

e edge compartment

$\mathrm{v} \quad$ varying

\footnotetext{
${ }^{*}$ Corresponding author. Present address: Sociedade Portuguesa de Inovacao, Edificio "Les Palaces", Rua Julio Dinis, 242 - Piso 2 - Sala 208, 4050 Porto, Portugal. Tel.: +351-2-6976400; fax: +351-2-6099164; e-mail: spi@mail.telepac.pt
}

\section{Introduction}

Deep-fat frying is widely used in food processing. Between the numerous fried products, potatoes are the most important ones from a point of view of market share. Frying may be seen as a high temperature drying process in a liquid fat medium. Fresh or frozen potato slices are immersed in the frying medium and as heating proceeds the water is evaporated and lost, vapour bubbles being formed at and released from the potato surface. A dry surface crust is formed and a $103^{\circ} \mathrm{C}$ isotherm evolves towards the centre (Pravisani \& Calvelo, 1986). Fat absorption into the voids created by the release of vapour occurs when the slice is removed from the frying medium as a result of a pressure drop, caused by the cooling of the product (Ufheil \& Escher, 1996; Gamble \& Rice, 1987). Thus, predicting water losses is most important to model and control the process.

Reported models often assume that the process may be described by mass transfer theory, being controlled either by internal diffusion mechanisms (Farkas, 1994; Rice \& Gamble, 1989; Kozempel, Tomasula \& Caig Jr., 1991) or by the resistance of the crust to mass transfer (Lamberg, 1990). Other authors suggest that heat transfer dominates the process (Keller \& Escher, 
1989; Ashkenazi, Mizrahi \& Berk, 1984). Indeed, both heat and mass transfer may be expected to play important roles in the process, and the changes of the potato structure and physical properties during frying, coupled to the build-up of internal stresses, further hinder the development of mechanistic models. Some fundamental models were however reported in literature (Farkas, 1994; Ngadi, Watts \& Correia, 1997), considering internal diffusion as the controlling step. These models provide a greater scientific insight, yet they are still based on over-simplified assumptions and imply the use of complex numerical methods, thus having high requirements in terms of computer software and time.

To avoid such complex models, compartmental models have been used in the study of water and solute transport during osmotic dehydration (Raoult-Wack et al., 1991) and intermittent drying of rice (Toyoda, 1988). Recently a three-compartment in series model was also reported for describing water losses in deep-fat frying of banana (Courtois, Trystram, Lemaire \& Wack, 1998). Visual observation of potato frying shows that the water loss rate is very slow at the beginning of frying and then abruptly increases up to a maximum after which water losses decrease approximately exponentially with time (Costa, Oliveira, Delaney \& Gekas, 1998). Furthermore, water loss is not uniform through the entire potato slice: it occurs first on the edges and, as heating proceeds, gradually evolves to the potato core. Structural and colour changes are also first perceived at the edges. This suggests the existence of two parallel compartments, with a time-dependent boundary condition, that may be related to the crust formation or heating to $103^{\circ} \mathrm{C}$ before evaporation.

The main objectives of this work were to assess whether a compartmental model could be used to describe water losses during deep-fat frying of potatoes and to assess the effect of process conditions on the model parameters.

\section{Materials and methods}

\subsection{Preparation of raw potato samples}

Slices $46 \pm 0.5 \mathrm{~mm}$ in diameter were cut from the flesh of potato tubers (CV. Van Gogh) with a Milano rotary slicer. Different thicknesses were tested: $1.5 \pm 0.1$ and $3.0 \pm 0.2 \mathrm{~mm}$. In addition, some experiments were made with french fries $\left(8.5 \pm 0.5 \times 8.5 \pm 0.5 \times 50 \pm 0.5 \mathrm{~mm}^{3}\right)$. Samples were cut from pith and perimedullary tissue, though when cutting french fries inclusion of other tissues was sometimes unavoidable. The potatoes were bought in a local market and prior to use they were stored at $15 \pm 5^{\circ} \mathrm{C}$ in a dark room for no longer than one month.

\subsection{Frying}

Frying was performed in a metal bath with $161 \mathrm{ca}-$ pacity. Temperature was controlled $\left( \pm 0.2^{\circ} \mathrm{C}\right)$ by a thermostatic head (Thermomix UB - Braun, Germany) and the oil was stirred to avoid temperature gradients. It was however noticed that agitation patterns were different from location to location and for that reason only two slices were fried at the same time in the same location, so that the hydrodynamic conditions would be always the same. Each potato sample was suspended on a stainless wire and immersed in the frying bath. After cutting, the slices were kept in a closed petri dish to avoid moisture loss prior to frying. The fried slices were surface dried with paper cloth, placed in a closed petri dish to avoid moisture loss prior to further analysis, and allowed to cool down to ambient temperature.

\subsection{The experiments}

A preliminary set of experiments was conducted to assess the adequacy of the model, with $1.5 \mathrm{~mm}$ thick potato slices and with french fries. In this set two temperatures were tested: $140^{\circ} \mathrm{C}$ and $180^{\circ} \mathrm{C}$. Sixteen sampling times and three to six replicates were analysed for each experiment. Sunflower oil with low oleic acid content was used as the frying medium.

A second set of experiments was performed based on a full factorial design at two levels, to assess the effect of different variables on the model parameters: temperature $\left(140^{\circ} \mathrm{C}\right.$ and $\left.180^{\circ} \mathrm{C}\right)$, slice thickness $(1.5$ and 3.0 $\mathrm{mm}$ ), oil variety (sunflower with $20 \%$ oleic acid and sunflower with $80 \%$ oleic acid) and oil use (fresh oil and oil heated for $8 \mathrm{~h}$ at $195^{\circ} \mathrm{C}$ ). The experiments were performed randomly. Twenty four sampling times and two replicates were analysed for each experiment.

Sunflower oil of low oleic acid content was obtained from ALCO (Porto, Portugal) and sunflower oil with high oleic acid content was obtained from FNM (Porto, Portugal).

\subsection{Moisture content determination}

The water content was measured gravimetricaly by the AOAC-984.25 method: samples were dried in a convection oven (Memmert, Schwabach, Germany) at $105 \pm 1{ }^{\circ} \mathrm{C}$ until constant weight $(16 \mathrm{~h}$ for french fries and 6-10 $\mathrm{h}$ for slices, depending on sample thickness).

\subsection{Oil penetration determination}

Some experiments were conducted with oil previously coloured before frying with $0.5 \mathrm{~g}$ of Sudan Red B (Fluka, Buchs, Switzerland) per litre of oil (this was earlier used by Keller, Escher and Solms (1986). After frying, the potato samples were quickly frozen in liquid 
nitrogen and freeze-dried in a Christ Alpha 1-4 freezedrier (Braun, Melsungen, Germany) model. The dried slices were cut longitudinally and observed with a video microscope Olympus 1000NM (Japan) with 50× magnification lenses.

\section{The mathematical model}

From visual observation, it was concluded that the frying process is faster at the potato edges than at the core, which may be due to geometrical effects: at the edges both heat and mass transfer occur radially and axially, whereas at the potato core radial transfer is not very important. Further evidence was provided by the analysis of oil penetration, as shown in Fig. 1: oil penetration occurred faster at the edges than at the potato core, and as oil penetrates into the voids created by the release of vapour (Ufheil \& Escher, 1996; Gamble \& Rice, 1987), this implies that water loss is also faster at the potato edges. Water loss was therefore modelled by a two-compartment model, a core and an edge compartment (see Fig. 1). The simplest dynamic model that can be considered for each compartment is a general first order response:

$\tau \frac{\mathrm{d} m}{\mathrm{~d} t}+m=f(t)$,

where $\tau$ is the compartment time constant, $m$ is its moisture content at time $t$ and $f(t)$ is an input function. The perturbation caused on the system at time zero (immersion of the potato in the frying medium) is not instantaneous, and it was assumed that it develops exponentially with time:

$\tau \frac{\mathrm{d} m}{\mathrm{~d} t}+m=m_{0} \mathrm{e}^{-\beta t}$,

where $m_{0}$ is the initial moisture content and $\beta$ is the delay constant of the input function.

The above equation describes the system dynamics as a general first-order response to an exponential input.

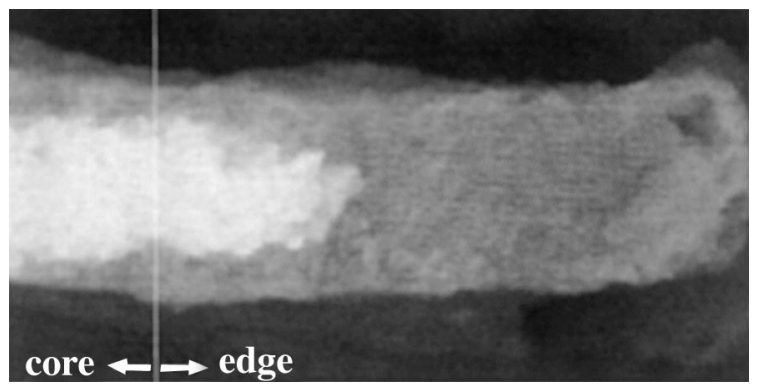

Fig. 1. Micrograph $(50 \times)$ of a longitudinal cut of a potato slice $(1.5$ $\mathrm{mm}$ ) fried in coloured oil at $140^{\circ} \mathrm{C}$ for $45 \mathrm{~s}$, with indication of the core and edge compartments. The darker region shows the oil penetration.
By simple mathematical manipulation, Eq. (2) may be written in a form more usual in kinetic models:

$\frac{\mathrm{d} m}{\mathrm{~d} t}=-k\left(m-m_{0} \mathrm{e}^{-\beta t}\right)$,

where $k$ is a rate constant (the reciprocal of $\tau$ ).

Eq. (3) shows that the gradient for water loss is timedependent, being zero at time zero. The integration of Eq. (3) yields:

$m=m_{0} \mathrm{e}^{-k t}+\frac{m_{0} k}{\beta-k}\left(\mathrm{e}^{-k t}-\mathrm{e}^{-\beta t}\right)$.

If no interaction is considered between the two-compartments, the amount of water in the potato at a given time is the weighed sum of the amount of water in each compartment:

$$
\begin{aligned}
\frac{m}{m_{0}}= & \alpha\left(\mathrm{e}^{-k_{\mathrm{c}} t}+\frac{k_{\mathrm{c}}}{\beta_{\mathrm{c}}-k_{\mathrm{c}}}\left(\mathrm{e}^{-k_{\mathrm{c}} t}-\mathrm{e}^{-\beta_{\mathrm{c}} t}\right)\right) \\
& +(1-\alpha)\left(\mathrm{e}^{-k_{\mathrm{e}} t}+\frac{k_{\mathrm{e}}}{\beta_{\mathrm{e}}-k_{\mathrm{e}}}\left(\mathrm{e}^{-k_{\mathrm{e}} t}-\mathrm{e}^{-\beta_{\mathrm{e}} t}\right)\right),
\end{aligned}
$$

where $\alpha$ is the fraction of water initially contained in the core compartment and the subscripts c and e refer respectively to the core and to the edge compartments.

When fitting this equation to the experimental data it was found that the $k$ and $\beta$ values, for a given compartment, were not statistically different. This allows simplification of Eq. (3) to:

$\frac{m}{m_{0}}=\alpha\left[\mathrm{e}^{-K_{\mathrm{c}} t}\left(1+K_{\mathrm{c}} t\right)\right]+(1-\alpha)\left[\mathrm{e}^{-K_{\mathrm{e}} t}\left(1+K_{\mathrm{e}} t\right)\right]$.

\section{Results and discussion}

The two-compartment model was fitted to the experimental data and the fits were compared with those obtained with other models commonly applied in literature: internal diffusion and lumped mass capacity system (i.e., first order kinetics due to the predominance of the external resistance to mass transfer). The solution of Fick's 2nd law for an infinite slab (Crank, 1975) was used for thin slices, whereas for french fries an infinite brick geometry was considered and the solution of Fick's 2nd law was combined with Newman's rule (Newman, 1936). Table 1 shows the estimates of the model parameters and some statistic parameters for the different models tested with the set of preliminary experiments. The fits to the experimental data are shown in Fig. 2. The results obtained show clearly that the compartmental model fits very well the experimental data ( $R^{2}$ between 0.994 and 0.999$)$. The diffusion and the lumped mass capacity models, though having in general high $R^{2}$, yield biased fits, except for the potato slices fried at $180^{\circ} \mathrm{C}$, where the lumped mass capacity model also gives a good fit. One should note that this model is 
Table 1

Parameters estimates (and standard errors) of the fits of various models to the water loss data

\begin{tabular}{|c|c|c|c|c|c|c|c|c|c|}
\hline \multirow[t]{2}{*}{$\begin{array}{l}T \\
\left({ }^{\circ} \mathrm{C}\right)\end{array}$} & \multirow[t]{2}{*}{$\begin{array}{l}\text { Potato } \\
\text { sample }\end{array}$} & \multicolumn{2}{|c|}{$\begin{array}{l}\text { Lumped mass capacity } \\
\text { model }\end{array}$} & \multicolumn{3}{|c|}{ Internal diffusion model } & \multicolumn{3}{|c|}{ Compartmental model } \\
\hline & & $\begin{array}{l}K \times 10^{2} \\
\left(\mathrm{~s}^{-1}\right)\end{array}$ & $R^{2}$ & $\begin{array}{l}D \times 10^{9} \\
\left(\mathrm{~m}^{2} \mathrm{~s}^{-1}\right)\end{array}$ & $R^{2}$ & $\alpha$ & $\begin{array}{l}k_{\mathrm{c}} \times 10^{2} \\
\left(\mathrm{~s}^{-1}\right)\end{array}$ & $\begin{array}{l}k_{\mathrm{e}} \times 10^{2} \\
\left(\mathrm{~s}^{-1}\right)\end{array}$ & $R^{2}$ \\
\hline 140 & $\mathrm{~S}-1.5^{\mathrm{a}}$ & $1.51 \pm 0.04$ & 0.9888 & $2.78 \pm 0.22$ & 0.9255 & $0.689 \pm 0.044$ & $2.40 \pm 0.10$ & $7.87 \pm 0.85$ & 0.9988 \\
\hline 180 & S-1.5 & $3.37 \pm 0.07$ & 0.9947 & $6.40 \pm 0.25$ & 0.9851 & $0.547 \pm 0.036$ & $4.38 \pm 0.20$ & $18.2 \pm 1.67$ & 0.9980 \\
\hline 140 & $\mathrm{FF}^{\mathrm{b}}$ & $0.377 \pm 0.023$ & 0.8473 & $4.92 \pm 0.37$ & 0.9218 & $0.620 \pm 0.013$ & $0.325 \pm 0.028$ & $4.53 \pm 0.25$ & 0.9936 \\
\hline 180 & FF & $0.463 \pm 0.017$ & 0.9525 & $6.93 \pm 0.65$ & 0.8978 & $0.641 \pm 0.020$ & $0.553 \pm 0.035$ & $4.50 \pm 0.37$ & 0.9959 \\
\hline
\end{tabular}

${ }^{a} \mathrm{~S}-1.5$ : slices $1.5 \mathrm{~mm}$ thick.

${ }^{\mathrm{b}} \mathrm{FF}$ : french fries.

a particular case of the compartmental model, when only one compartment is considered and when the delay is short $(\beta \rightarrow \infty)$. Both the diffusion and the lumped mass capacity models are not able to describe the initial delay generally observed in the experimental data. The values of the diffusion coefficients obtained $\left(2.78 \times 10^{-9}\right.$ $6.93 \times 10^{-9} \mathrm{~m}^{2} \mathrm{~s}^{-1}$ ) are comparable to those reported by other authors (e.g., Rice \& Gamble, 1989).

Fig. 3 shows the evolution of the moisture content in the core and in the edge compartment for the preliminary experiments. For the thin slices, the edge compartment is basically dry after $1 \mathrm{~min}$ at $140^{\circ} \mathrm{C}$ and $30 \mathrm{~s}$ at $180^{\circ} \mathrm{C}$. The sigmoidal behaviour is much more evident in the core compartment, due to the longer time required for the time-dependent boundary condition to stabilise (see Fig. 4). For french fries, it is curious to note that after 2 min of frying the edge compartment is virtually dry, whereas the core compartment lost only a minor amount of water (Fig. 3(c) and (d)). The driving force for mass transfer shows a maximum with time (Fig. 5), much more delayed for the core compartment in french fries.

The time-dependent boundary condition applied to each compartment could also be seen from the per-
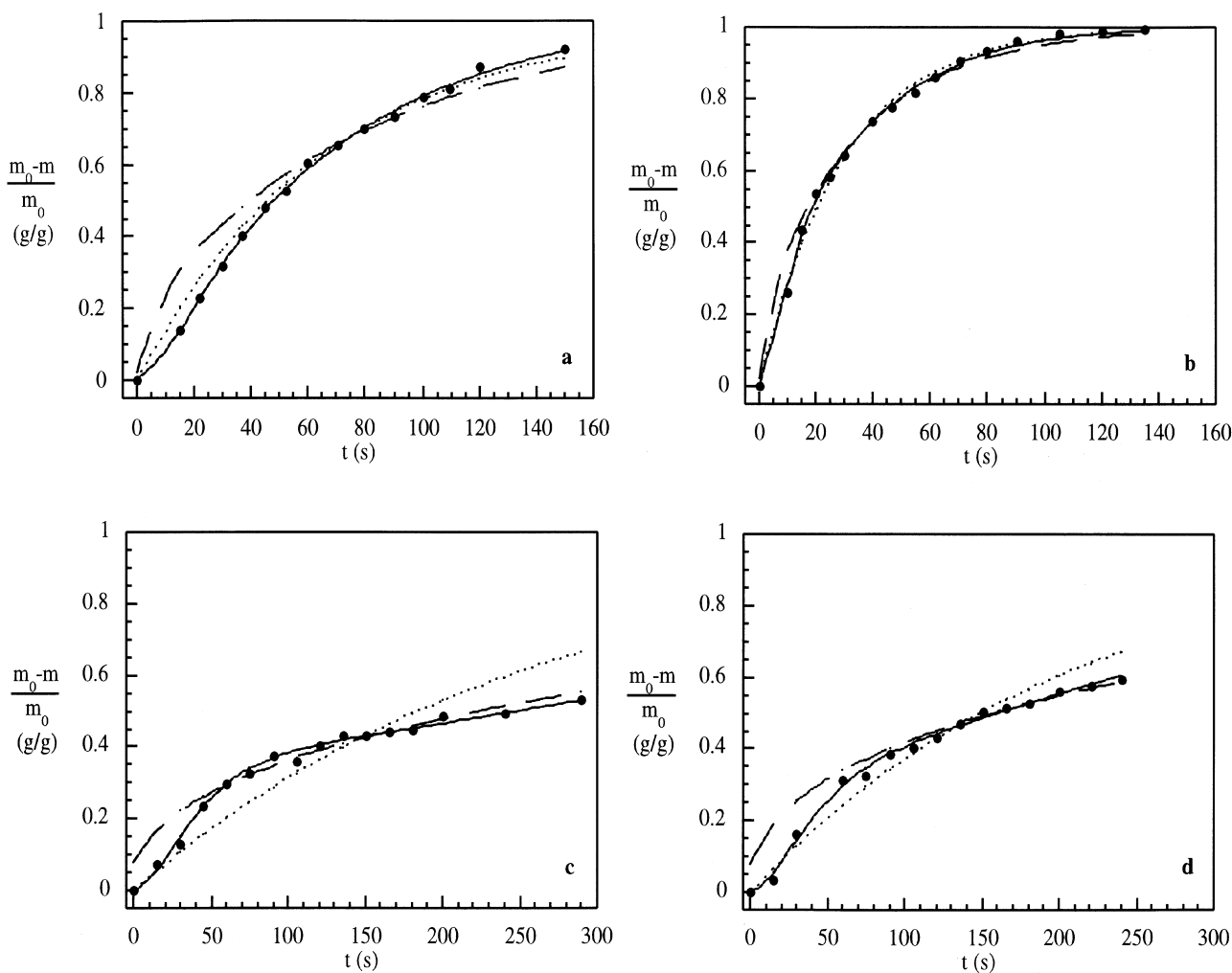

Fig. 2. Fit of selected mathematical models to water losses: (a) $1.5 \mathrm{~mm}$ potato slices at $140^{\circ} \mathrm{C}$; (b) $1.5 \mathrm{~mm}$ potato slices at $180^{\circ} \mathrm{C}$; (c) french fries at

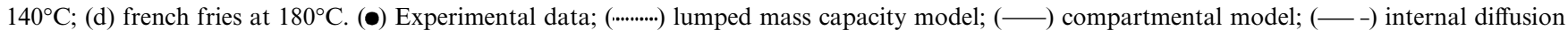
model. 

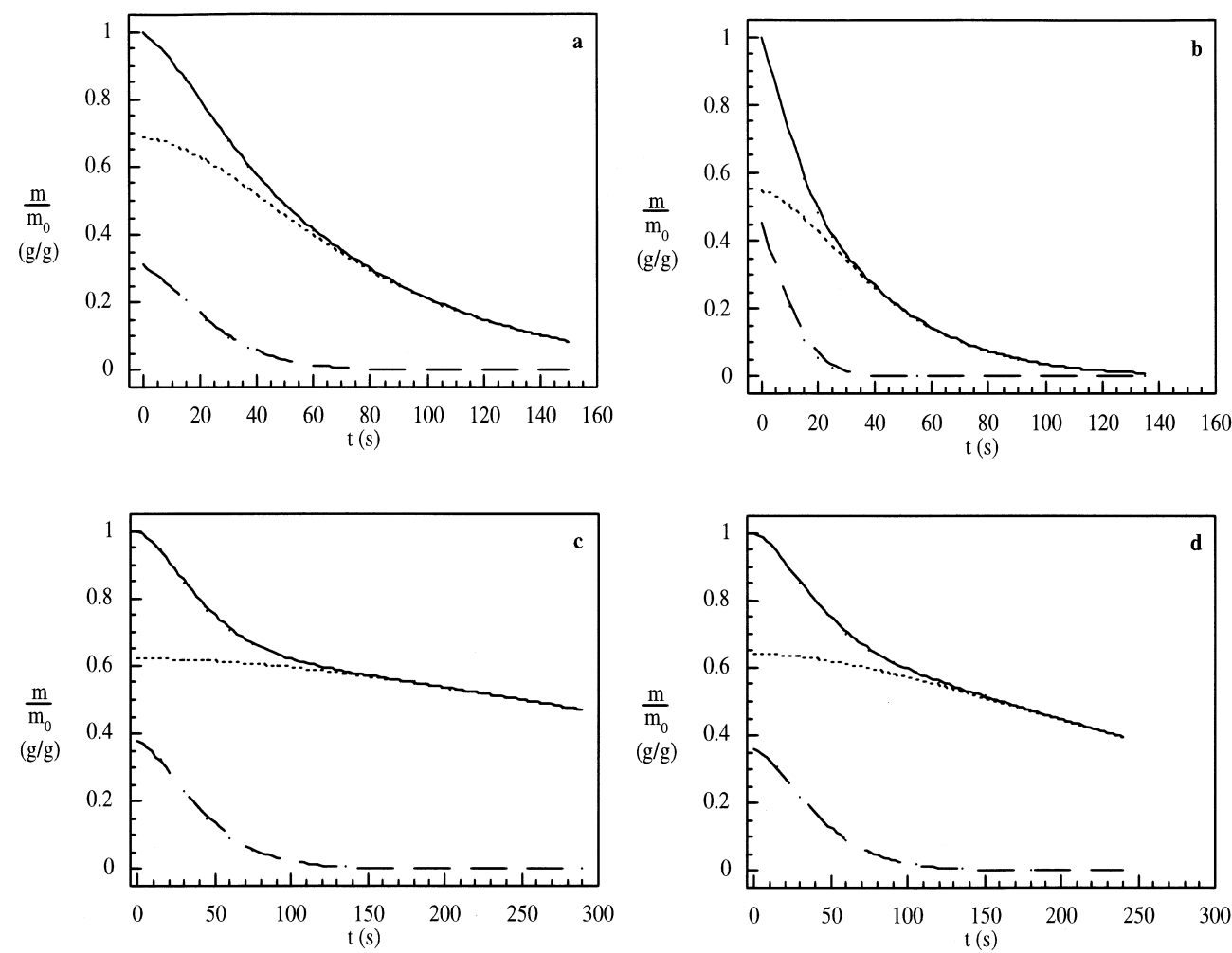

Fig. 3. Evolution of the fractional water content in the whole potato and in the two-compartments, as predicted by the compartmental model: (a) 1.5 $\mathrm{mm}$ potato slices at $140^{\circ} \mathrm{C}$; (b) $1.5 \mathrm{~mm}$ potato slices at $180^{\circ} \mathrm{C}$; (c) french fries at $140^{\circ} \mathrm{C}$; (d) french fries at $180^{\circ} \mathrm{C}$. (..........) Core; (--) edge; $(-)$ global.
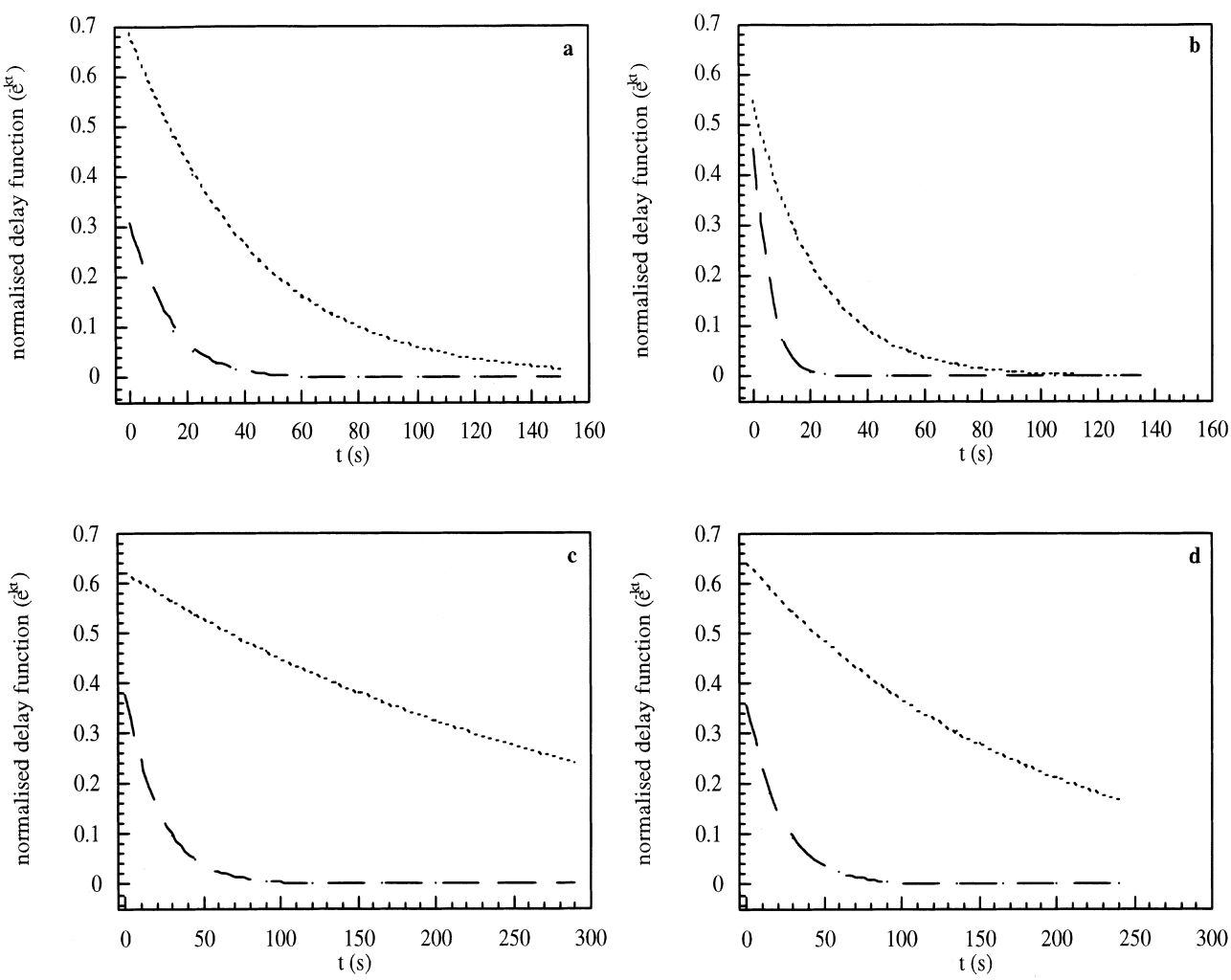

Fig. 4. Evolution of the normalised delay function $\left(\mathrm{e}^{-k t}\right)$ in two-compartments, as predicted by the compartmental model: (a) $1.5 \mathrm{~mm}$ potato slices at $140^{\circ} \mathrm{C}$; (b) $1.5 \mathrm{~mm}$ potato slices at $180^{\circ} \mathrm{C}$; (c) french fries at $140^{\circ} \mathrm{C}$; (d) french fries at $180^{\circ} \mathrm{C}$. (..........) Core; (- - ) edge. 

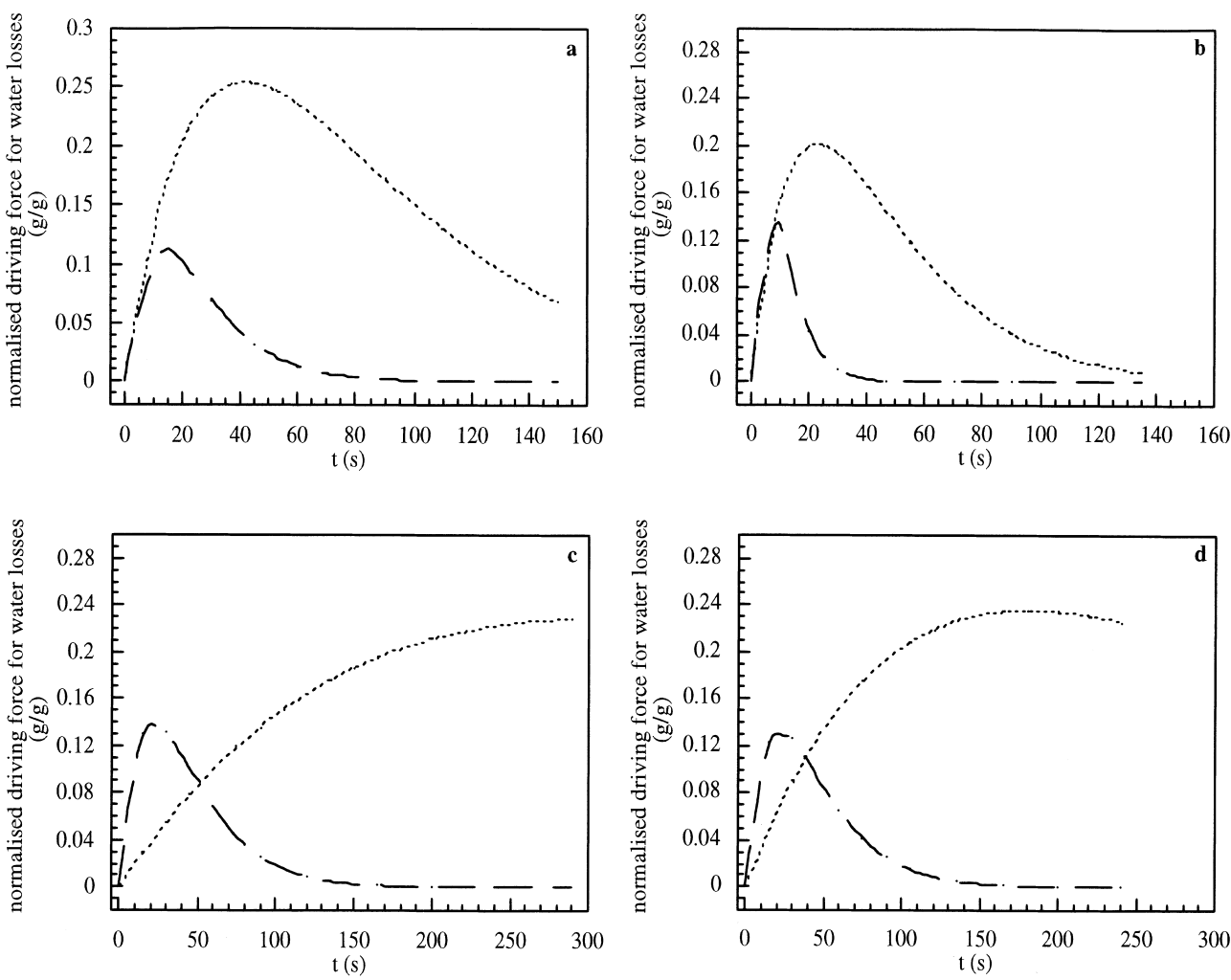

Fig. 5. Evolution of the normalised driving force $\left(\left(m-m_{0} \mathrm{e}^{-k t}\right) / m_{0}\right)$ in two-compartments, as predicted by the compartmental model: (a) $1.5 \mathrm{~mm}$ potato slices at $140^{\circ} \mathrm{C}$; (b) $1.5 \mathrm{~mm}$ potato slices at $180^{\circ} \mathrm{C}$; (c) french fries at $140^{\circ} \mathrm{C}$; (d) french fries at $180^{\circ} \mathrm{C}$. (..........) Core; (--) edge.

spective of a varying rate constant $\left(k_{\mathrm{v}}\right)$. Eqs. (3) and (4) can be combined, considering $k=\beta$, yielding the following equation:

$\frac{\mathrm{d} m}{\mathrm{~d} t}=-k_{\mathrm{v}} m$,

where

$k_{\mathrm{v}}=\frac{k^{2} t}{1+k t}$.

This equation shows that this apparent rate constant starts at zero and increases with time, levelling off at the values of $k_{\mathrm{c}}$ and $k_{\mathrm{e}}$, respectively for the core and the edge compartments. Fig. 6 shows the evolution of this timedependent rate constant on time. It can be seen that the rate constant starts at zero, due to the delay, and increases faster for the edge compartment and for crisps, as this increase depends on the $k_{\mathrm{c}}$ and $k_{\mathrm{e}}$ values. Results earlier reported (Costa et al., 1998) showed that the heat transfer coefficient from the frying medium to the potato increases up to a maximum and then decreases. Thus, this time dependent behaviour cannot be explained by the changes in the rate of heat transfer from the oil to the potato only, as when the heat transfer coefficient starts decreasing, this apparent constant rate continues increasing, though at a moderate rate.

To further assess the applicability of the proposed model and to get some insight into the dependence of the model parameters on the process conditions, the model was applied to a set of experiments with potato slices based on a factorial design of the following variables at two levels: (i) oil temperature, (ii) slice thickness, (iii) percentage of oleic acid in sunflower oil and (iv) oil use. The estimates of the model parameters are presented in Table 2 and the Pareto charts for the effects are presented in Fig. 7. The model provided very good fits for all the conditions tested $\left(R^{2}\right.$ between 0.984 and 0.999).

The parameter $\alpha$ is not statistically affected by any of the variables tested, though slightly greater for the thinner potatoes. Its average value was 0.63 , and if one assumes that the water is evenly distributed through the whole potato slice, this means that the core compartment corresponds to the potato slice up to a radius of 18 $\mathrm{mm}$ and the remaining $5 \mathrm{~mm}$ constitute the edge compartment.

The rate constant of the edge compartment is between 2 and 40 times greater than that of the core compartment. The slice thickness is the variable that affects the rate constants the most. Increased thickness decreases the rate constant, owing to geometry effects: thicker slices have a smaller specific area thus reducing the relative area available for water loss, the internal pathway is longer and more heat is required to evaporate the water; also, the surface crust that hinders water loss may play a major role on the thicker potatoes, as the thinner potatoes have a crust type structure already 
Table 2

Estimates of the parameters (and standard errors) of the compartmental model for a factorial design at two levels of the factors temperature, slice thickness, oil type and oil use

\begin{tabular}{|c|c|c|c|c|c|c|c|c|}
\hline \multirow[t]{2}{*}{$\begin{array}{l}\text { Experiment } \\
\text { number }\end{array}$} & \multicolumn{4}{|l|}{$\begin{array}{l}\text { Levels of } \\
\text { the factors }\end{array}$} & \multicolumn{4}{|l|}{$\begin{array}{l}\text { Parameters } \\
\text { estimates }\end{array}$} \\
\hline & $\begin{array}{l}\text { Tempera- } \\
\text { ture }\left({ }^{\circ} \mathrm{C}\right)\end{array}$ & $\begin{array}{l}\text { Slice } \\
\text { thickness } \\
(\mathrm{mm})\end{array}$ & $\begin{array}{l}\text { Oil type (\% } \\
\text { of oleic acid } \\
\text { in sunflower } \\
\text { oil) }\end{array}$ & Oil use & $\alpha(\mathrm{g} / \mathrm{g})$ & $k_{\mathrm{c}} \times 10^{2}\left(\mathrm{~s}^{-1}\right)$ & $\begin{array}{l}k_{\mathrm{e}} \times 10^{2} \\
\left(\mathrm{~s}^{-1}\right)\end{array}$ & $R^{2}$ \\
\hline 1 & 180 & 1.5 & 20 & Fresh oil & $0.524 \pm 0.050$ & $6.30 \pm 0.40$ & $25.0 \pm 2.83$ & 0.9956 \\
\hline 2 & 140 & 1.5 & 80 & Fresh oil & $0.781 \pm 0.025$ & $2.88 \pm 0.10$ & $31.2 \pm 23.3$ & 0.9935 \\
\hline 3 & 140 & 1.5 & 20 & Heated $^{\mathrm{a}}$ & $0.766 \pm 0.095$ & $3.07 \pm 0.28$ & $15.0 \pm 13.0$ & 0.9843 \\
\hline 4 & 140 & 3.0 & 20 & Heated & $0.493 \pm 0.022$ & $0.695 \pm 0.083$ & $3.57 \pm 0.18$ & 0.9984 \\
\hline 5 & 140 & 3.0 & 20 & Fresh oil & $0.536 \pm 0.017$ & $0.608 \pm 0.017$ & $4.27 \pm 0.22$ & 0.9981 \\
\hline 6 & 140 & 3.0 & 80 & Heated & $0.555 \pm 0.033$ & $0.637 \pm 0.032$ & $3.82 \pm 0.38$ & 0.9952 \\
\hline 7 & 180 & 3.0 & 20 & Fresh oil & $0.515 \pm 0.024$ & $1.07 \pm 0.06$ & $9.50 \pm 0.87$ & 0.9944 \\
\hline 8 & 180 & 3.0 & 80 & Fresh oil & $0.560 \pm 0.015$ & $1.02 \pm 0.03$ & $10.3 \pm 0.73$ & 0.9972 \\
\hline 9 & 180 & 3.0 & 80 & Heated & $0.621 \pm 0.019$ & $0.670 \pm 0.017$ & $4.05 \pm 0.25$ & 0.9986 \\
\hline 10 & 140 & 3.0 & 80 & Fresh oil & $0.839 \pm 0.066$ & $2.93 \pm 0.17$ & $12.8 \pm 8.72$ & 0.9942 \\
\hline 11 & 140 & 1.5 & 20 & Fresh oil & $0.205 \pm 0.193$ & $1.88 \pm 0.87$ & $4.70 \pm 0.58$ & 0.9949 \\
\hline 12 & 180 & 1.5 & 80 & Heated & $0.561 \pm 0.056$ & $4.62 \pm 0.33$ & $21.2 \pm 3.67$ & 0.9912 \\
\hline 13 & 180 & 1.5 & 20 & Heated & $0.666 \pm 0.075$ & $6.08 \pm 0.37$ & $18.8 \pm 3.33$ & 0.9968 \\
\hline 14 & 180 & 3.0 & 80 & Heated & $0.603 \pm 0.603$ & $1.16 \pm 0.07$ & $9.20 \pm 1.30$ & 0.9926 \\
\hline 15 & 180 & 1.5 & 80 & Fresh oil & $0.626 \pm 0.043$ & $6.47 \pm 0.23$ & $20.2 \pm 2.00$ & 0.9990 \\
\hline 16 & 180 & 3.0 & 20 & Heated & $0.582 \pm 0.026$ & $1.25 \pm 0.06$ & $9.23 \pm 0.95$ & 0.9958 \\
\hline
\end{tabular}

${ }^{\mathrm{a}}$ For $8 \mathrm{~h}$ at $195^{\circ} \mathrm{C}$.
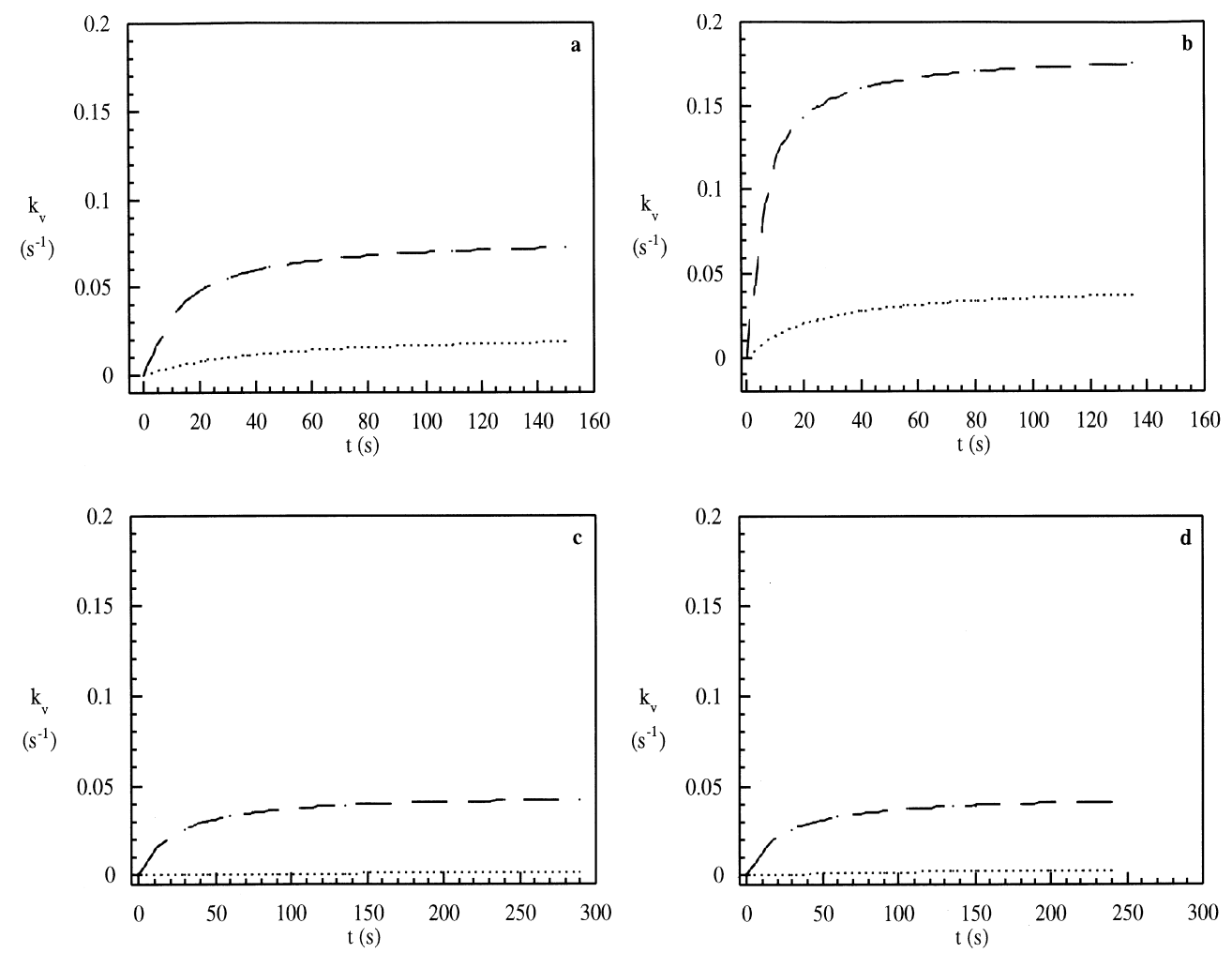

Fig. 6. Evolution of the varying constant rate in two-compartments, as predicted by the compartmental model: (a) $1.5 \mathrm{~mm}$ potato slices at $140^{\circ} \mathrm{C}$; (b) $1.5 \mathrm{~mm}$ potato slices at $180^{\circ} \mathrm{C}$; (c) french fries at $140^{\circ} \mathrm{C}$; (d) french fries at $180^{\circ} \mathrm{C}$. (...........) Core; (- - ) edge. 

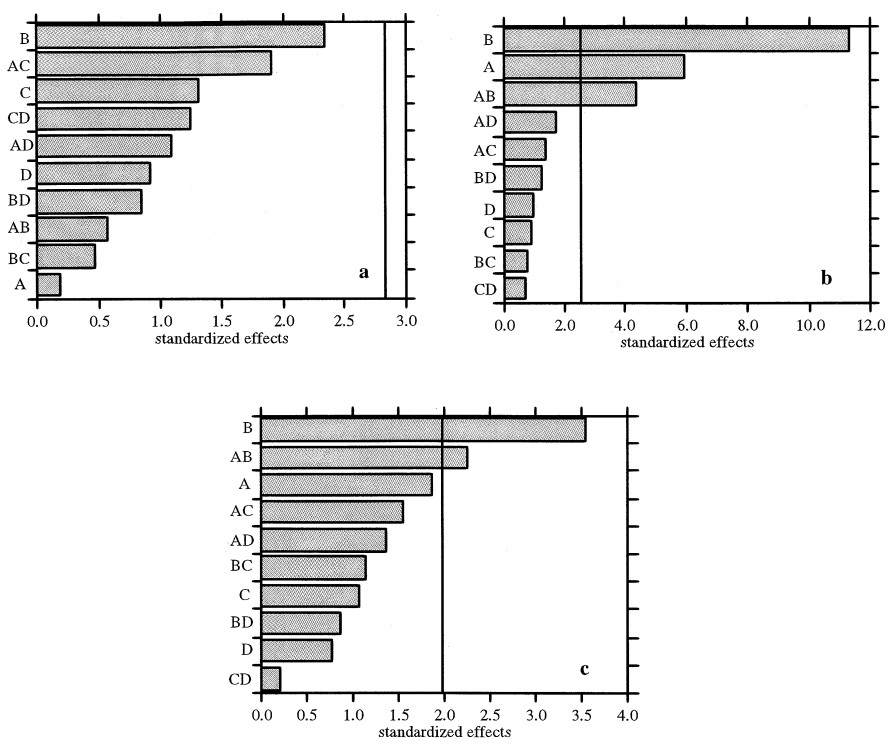

Fig. 7. Standardised Pareto charts of the effects of temperature (A), potato slice thickness (B), oil type (C) and oil use (D) on the parameters of the compartmental model: (a) $\alpha$, (b) $k_{\mathrm{c}}$; (c) $k_{\mathrm{e}}$. The vertical line represents the limit of the significance level at $95 \%$.

at relatively short frying times. This effect is more evident for the rate constant of the core compartment. Temperature also plays a significant role on the rate constant of the core compartment, showing an interaction with thickness: the greater the temperature the greater the rate constant, as expected, but this is particularly important for the thinner slices. On the other hand, temperature does not affect the rate constant of the outer compartment at a $95 \%$ significance level.

The frying medium and the oil use did not show any significant effect $(P<0.05)$. The two frying media tested differed only on the oleic acid content. At room temperature the oil richer in oleic acid is more viscous, but as temperature increases this difference levels off (Noureddini, Teoh \& Clements, 1992; Toro-Vasquez \& InfanteGuerreo, 1993), explaining why no significant differences were detected when frying the potatoes in the two different media. Physical properties change with oil use (Blumenthal \& Stier, 1991): viscosity, thermal conductivity and specific gravity increase, while heat capacity, surface tension and interfacial tension decrease. In our experiments, the oil heated for $8 \mathrm{~h}$ at $195^{\circ} \mathrm{C}$ presented a reddish colour and an off-flavour. Yet, this was found not to affect water loss at a $95 \%$ significance level.

\section{Conclusions}

The proposed compartmental model showed to fit very well the experimental data of water losses during frying. The core compartment was found to contain about $63 \%$ of the initial potato water content. The rate constants of the two-compartments are very sensitive to slice thickness, whereas temperature affects only the rate constant of the core compartment. No significant effects were detected in terms of oil type or oil use.

\section{Acknowledgements}

The first author acknowledges financial support from Fundação para a Ciência e a Tecnologia (FCT) through "Sub-programa Ciência e Tecnologia do $2^{\circ}$ Quadro Comunitário de Apoio".

\section{References}

Ashkenazi, N., Mizrahi, S., \& Berk Z. (1984). Heat and mass transfer in frying. In B. M. McKenna, Engineering and food, vol. 1 (pp. 109116). London: Elsevier.

Blumenthal, M. M., \& Stier, R. F. (1991). Optimization of deep-fat frying operations. Trends-in-Food-Science-\&-Technology, 2(6), 144148

Costa, R., Oliveira, F. A. R., Delaney, O., \& Gekas, V. (1998). Analysis of the heat transfer coefficient during potato frying. Journal of Food Engineering, 39(3), 293-299.

Courtois, F., Trystram, G., Lemaire, R., \& Wack, A.L. (1998). Modelling of deep fat frying of banana using a compartmental approach and boiling's theory. In C. B. Akritidis, D. MarinosKouris, \& G. D. Saravacos, Proceedings of the 11th International Drying Symposium (pp. 1452-1459). Thessaloniki: Ziti Editions.

Crank, J. (1975) The mathematics of diffusion (2nd ed.). Bristol: Oxford University Press.

Farkas, B. E. (1994). Modeling immersion frying as a moving boundary problem. Ph.D. Dissertation, University of California, Davis, USA.

Gamble, M. H., \& Rice, P. (1987). Effect of pre-fry drying of oil uptake and distribution in potato crisp manufacture. International Journal of Food Science and Technology, 22, 535-548.

Keller, C., \& Escher, F. (1989). Heat and mass transfer during deep fat frying of potato products. Poster presented at the Fifth International Congress on Engineering and Food. Cologne, Germany. 
Keller, C., Escher, F., \& Solms, J. (1986). A method for localizing fat distribution in deep-fat fried potato products. Lebensm.-Wiss.u.Technol., 19, 346-348.

Kozempel, M. F., Tomasula, P. M., \& Caig, J. C. (1991). Correlation of moisture and oil concentration in french fries. Lebensm. Wiss. u.Technol., 24, 445-448.

Lamberg, I. (1990). Transport phenomena in potato tissues: A study with application to blanching, drying and frying. Ph.D. Dissertation. Lund University, Sweden.

Newman, A. B. (1936). Heating and cooling of rectangular and cylindrical solids. Industrial and Engineering Chemistry, 28, 545548 .

Ngadi, M. O., Watts, K. C., \& Correia, L. R. (1997). Finite element method modelling of moisture transfer in chicken drum during deep-fat frying. Journal of Food Engineering, 32, 11-20.

Noureddini, H., Teoh, B. C., \& Clements, L. D. (1992). Viscosities of vegetable oils and fatty acids. Journal of the American Oil Chemists' Society, 69, 1189-1191.
Pravisani, C. I., \& Calvelo, A. (1986). Minimum cooking time for potato strip frying. Journal of Food Science, 51, 614-617.

Raoult-Wack, A. L., Petitdemange, F., Giroux, F., Rios, G., Guilbert, S., \& Lebert, A. (1991). Simultaneous water and solute transport in shrinking media - Part 2. A compartmental model for the control of dewatering and impregnation soaking processes. Drying Technology, 9, 613-630.

Rice, P., \& Gamble, M. H. (1989). Modeling moisture loss during potato slice frying. International Journal of Food Science Technology, 24, 183-187.

Toro-Vasquez, J. F., \& Infante-Guerreo, R. (1993). Regressional models that describe oil absolute viscosity. Journal of the American Oil Chemists' Society, 70, 1115-1119.

Toyoda, K. (1988). Study on intermittent drying of rough rice in a recirculation dryer. In Proceedings of the International Drying Symposium'88, Versailles, France, O.P., p. 171.

Ufheil, G., \& Escher, F. (1996). Dynamics of oil uptake during deepfat frying of potato slices. Lebensm.-Wiss.u.-Technol., 29, 640-644. 